Revista Brasileira de Agricultura Irrigada v.10, nº.6, p. 999 - 1010, 2016

ISSN 1982-7679 (On-line)

Fortaleza, CE, INOVAGRI - http://www.inovagri.org.br

DOI: $10.7127 /$ rbai.v10n600441

Protocolo 441.16 - 29/04/2016 Aprovado em 20/12/2016

\title{
ÍNDICE DE QUALIDADE DA ÁGUA NAS NASCENTES DO RIO PIAUITINGA-SE POR ANÁLISE MULTIVARIADA E O USO NA IRRIGAÇÃO
}

\author{
Neuma Rúbia Figueiredo Santana ${ }^{1}$, Antenor Oliveira Aguiar Neto $^{2}$, Marinoé Gonzaga da \\ Silva $^{3}$, Carlos Alexandre Borges Garcia ${ }^{4}$
}

\begin{abstract}
RESUMO
As nascentes são fontes essenciais que jorram na superfície terrestre, tornando-se primordiais para a formação dos rios. A nascente do rio Piauitinga forma uma das importantes bacias hidrográficas para o Estado de Sergipe. Nesse sentido, este trabalho teve como objetivo estudar a variação das características físicas e químicas da água desta nascente por meio de métodos de análise multivariada, utilizando análise fatorial através das técnicas de análise da componente principal e análise dos fatores comuns e, dessa forma, indicar quais as variáveis significativas para a sua qualidade. As amostras de água foram coletadas na camada superficial do corpo d'água, nos meses de outubro de 2009, fevereiro, abril e agosto de 2010. Os parâmetros analisados foram $\mathrm{pH}$, turbidez, cor, condutividade elétrica, sólidos totais solúveis, dureza, nitrato e amônia. A análise multivariada partiu de uma matriz de 08 x 20 (linhas x colunas), sendo que as linhas representam os parâmetros e as colunas observações. Assim, há correlação significativa entre $\mathrm{pH}$ e dureza, ou seja, o aumento do $\mathrm{pH}$ está associado a um aumento da dureza, o mesmo pode ser verificado com a turbidez e cor. Amônia apresentou correlação negativa com os sólidos totais solúveis e dureza, indicando que o aumento de uma variável provoca redução na outra. Os resultados obtidos apontaram três fatores de índice de qualidade: condutividade elétrica e dureza, a cor e a turbidez e os sólidos totais solúveis. A sustentabilidade desses índices deve ser mantida por fiscalização da comunidade e dos órgãos competentes.
\end{abstract}

Palavras-chave: Bacia Hidrográfica. Recursos Hídricos. Sustentabilidade.

\section{INDEX OF QUALITY OF WATER AT THE HEADWATERS OF RIVER PIAUITINGA-SE BY MULTIVARIATE ANALYSIS AND USE IN IRRIGATION}

\footnotetext{
ABSTRACT

${ }^{1}$ Doutoranda em desenvolvimento e meio ambiente pela Universidade Federal de Sergipe (UFS), e-mail: rubiafs@gmail.com

${ }^{2}$ Doutor em agronomia, Pós-doc em Recursos Hidricos pela Universidade Federal de Santa Catarina. Professor associado da universidade Federal de Sergipe/Campus São Cristóvão, e-mail: antenor.ufs@gmail.com

${ }^{3}$ Doutora em Desenvolvimento e Meio Ambiente da Universidade Federal de Sergipe (UFS). Professora do Instituto Federal de Sergipe/Campus São Cristóvão, e-mail: marinoegonzaga@gmail.com

${ }^{4}$ Doutor em química pela Unicamp. Professor associado da universidade Federal de Sergipe/Campus São Cristóvão, e-mail: cgarcia@ufs.br
} 
The headwaters are important resources that spouts on the surface of the Earth, getting crucial to the formation of the rivers. The headwater of the river Piauitinga makes one of the most important hydrographic basins to the state of Sergipe. Therefore, this study aimed to study the variation of physical and chemical characteristics of water this spring using multivariate analysis methods, using factorial analysis through the analysis techniques the main component and analysis of common factors and thus, indicate which the significant variables for their quality. The water samples were collected from the superficial layer of the water body, in the months of October 2009, February, April and August of 2010. The analyzed parameters were $\mathrm{pH}$, turbidity, color, electrical conductivity, total soluble solids, hardness, nitrite and ammonia. Multivariate analysis came from a matrix of 08 x 20 (lines x columns), and the lines represent the parameters and columns observations. Thus, there is a significant correlation between $\mathrm{pH}$ and hardness, in other words, the increase in $\mathrm{pH}$ is associated with an increase of the hardness, and this can be checked for turbidity and color. Ammonia was negatively correlated with the total soluble solids and hardness, indicating that the increase causes a decrease in the other variable. The results showed three quality index factors: conductivity and hardness, color and turbidity, and total soluble solids. The sustainability of these levels should be maintained for inspection of the community and the competent bodies.

Keywords: Hydrographic Basins; Water Resources; Sustainability

\section{INTRODUÇÃO}

As nascentes são fontes essenciais que jorram na superfície terrestre tornando-se primordiais para a formação dos rios. São caracterizadas como ambientes singulares, cuja complexidade ambiental ainda é pouco interpretada. Outrora, pouco se discutia sobre degradação de nascentes, devido à grande divulgação de que esses recursos naturais estão em sua maioria em lugares altos e protegidos por matas, não atrativos à ocupação humana, já que o desenvolvimento urbano é característico em lugares de fácil captação de recursos naturais.

Hoje, tem-se discutido com maior frequência acerca das condições degradadas das nascentes de importantes rios e dos impactos causados por ações do homem a esses recursos naturais. Muitas pesquisas realizadas nas áreas ambientais demonstram grande preocupação na preservação desses recursos, tanto de suas áreas (matas ciliares, por exemplo) como da qualidade de suas águas. Para Pinto et al. (2004), a qualidade de água das nascentes de uma bacia hidrográfica pode ser alterada por múltiplos fatores, enfatizandose o tipo do solo e seu uso e, por isso, faz-se necessário o estudo das interações dos recursos e das ações antrópicas na bacia hidrográfica.
Segundo Castro (2007), em qualquer atividade deve-se evitar a poluição que venha comprometer a vida humana e dos animais. Tal consciência e atitude de preservação garantiriam a qualidade das águas das nascentes. Para Tucci (2001), a qualidade da água depende das condições geológicas, da cobertura vegetal e, principalmente, das ações do homem, que altera o solo tanto para uso rural como urbano, lançamento de resíduos domésticos, industrial e agrícola em águas. Porém, o termo qualidade não se refere ao estado de pureza, mas a alguns aspectos como físicos e químicos, que caracterizam os elementos presentes em determinado meio.

Salienta-se que, além dos contaminantes químicos, a poluição da água também pode ser resultado de toda e qualquer ação que acarrete aumento excessivo de elementos minerais e matéria orgânica no corpo hídrico. E para a verificação dos possíveis contaminantes presentes em um curso d’água torna-se necessária a análise desses componentes. Buss (2008) acredita que a falta de informação sobre a qualidade dos ecossistemas aquáticos impede a sistematização de bancos de dados abrangentes, prejudicando o direcionamento de políticas e organização de planos de ação para os recursos hídricos. Além desses aspectos, a sociedade deve entender que é necessária a 

MULTIVARIADA E O USO NA IRRIGAÇÃO

disponibilidade de água com padrões de qualidade adequada aos seus respectivos usos, tanto à atual como às futuras gerações (AGUIAR NETTO; MAGALHÃES FILHO; ROCHA, 2010).

Contudo, quando ao se obter informações relativas à qualidade e quantidade da água, o elevado número de parâmetros tende a dificultar a interpretação dos dados. Dessa forma, a análise multivariada vem sendo amplamente utilizada por permitir avaliar a qualidade da água por meio da condensação de informações (SOH; ABDULLAH, 2007; KUMARESAN; RIYAZUDDIN, 2008; SOJKA et al.,2008; SCHAGERL et al., 2010; SONG et al., 2011).

Nesse sentido, este trabalho teve como objetivo estudar a variação das características físicas e químicas da água da bacia hidrográfica do rio Piauitinga/SE por meio de métodos de análise multivariada, o qual permite identificar as variáveis mais importantes na qualidade da água para irrigação.

\section{MATERIAIS E MÉTODOS}

\section{Área de estudo}

A bacia hidrográfica do rio Piauitinga localiza-se entre as coordenadas $10^{\circ} 34^{\prime} 10^{\prime \prime} \mathrm{e}$ $10^{\circ} 45^{\prime} 12^{\prime \prime}$ S e $37^{\circ} 22^{\prime} 20^{\prime \prime}$ e $37^{\circ} 34^{\prime} 22^{\prime \prime}$ W, apresenta uma área total de $418,2 \mathrm{~km}^{2}$, cujo leito principal é perene em extensão de 150 km. O território desta bacia é composto por cinco municípios: Estância, Lagarto, Salgado, Boquim e Itaporanga D'ajuda, ou seja, quase $11 \%$ da bacia hidrográfica do rio Piauí (OLIVEIRA, 2002). Dentre os rios pertencentes à bacia do rio Piauí, apenas o rio Piauitinga possui água doce, responsável pelo abastecimento para consumo humano de todos os municípios da região sul e centro sul do Estado de Sergipe, totalizando 24 municípios (CARVALHO; SANTANA, 2009).

O presente trabalho foi desenvolvido no município de Lagarto-SE, o qual encontra-se no limite geográfico com área de $969,22 \mathrm{~km}^{2}$ de extensão, e com $183 \mathrm{~m}$ de altitude média em relação ao nível do mar (SANTOS, 2009).
O clima da região, segundo Fontes e Santos (1999), é megatérmico subúmido C1A’a', apresentando moderados excedentes hídricos de inverno, com estação seca bem definida e deficiência hídrica no verão. A temperatura média anual em 2009 foi de 24,4 ${ }^{\circ} \mathrm{C}$; a precipitação total de $1.247,3 \mathrm{~mm}$ e com média anual em torno de 103,9 mm (COHIDRO, 2010).

Os solos na região de Lagarto são do tipo planasolo solódico eutrófico (Plse) e, por serem de textura arenosa, são de baixa fertilidade; assim, por possuírem elevada acidez dificultam por muito tempo os cultivos agrícolas, de forma que são necessários aditivos para o plantio (SANTOS, 2009). Para Magalhães (2009), as características marcantes dos solos no alto curso do rio Piauitinga são: o forte hidromorfismo, além de quebra de relevo especificamente no entorno das nascentes, baixadas e um único sopé de encosta suave de topo de tabuleiros costeiros.

A vegetação deste município nos primórdios era formada pela floresta da Mata Atlântica, pela Mata do Agreste, pelo cerrado e pela caatinga; atualmente, a Mata do Agreste e as pastagens é que ocupam grande parte da área. Havia, em 1996, 2.724 hectares de matas e florestas; em 2006, a realidade era de 1.780 ha, notando-se uma significativa perda vegetal em um período de 10 anos (SEMARH, 2010).

De acordo com o Instituto Brasileiro de Geografia e Estatística (IBGE, 2010), a população da bacia do rio Piauitinga é de quase 229.774 habitantes, porém o município de Lagarto destaca-se com a maior representação populacional, em torno de 94.852 habitantes. A sede do município e as principais vilas dispõem de abastecimento de água, captada de rio e poços artesianos, e distribuída pela Companhia de Saneamento de Sergipe (DESO). O esgotamento sanitário é efetuado através de fossas sépticas e comuns, enquanto o lixo coletado é transportado por caçamba e depositado a céu aberto (SRH, 2002). Salientase que, tanto a distribuição de água quanto a coleta de lixo não são realizadas na maior parte da zona rural. 
$\mathrm{Na}$ agricultura, destacam-se as lavouras de mandioca, laranja, maracujá, milho, feijão, fumo e, em menores proporções, o cultivo de batata-doce, amendoim, banana, tomate, fava, coco-bahia e mamão (IBGE, 2008). Em 1996, a lavoura temporária era cultivada em 6.309 ha, chegando, em 2006, a um cultivo de 42.449 ha desse município (SEMARH, 2010). Como principais efetivos de rebanhos estão a criação de bovinos, equinos e suínos; na avicultura, destacam-se os galináceos; no setor de saúde, o município é servido por um hospital público e 16 postos/centros de saúde (BOMFIM; COSTA; BENVENUTI, 2002).

\section{Pontos de amostragem}

Das 28 nascentes classificadas no município de Lagarto, por meio do projeto Adote um Manancial, no ano de 2007, juntamente com a Universidade Federal de Sergipe (UFS) e a Promotoria deste município, foram selecionados quatro referentes às nascentes: 01, 05, 08, 19, além de um novo ponto, cadastrado como nascente 29, totalizando cinco pontos para análise. Esses pontos encontram-se localizados no alto curso do rio Piauitinga.

Todos os pontos foram georreferenciados com auxílio do Sistema de Posicionamento Global (GPS), com datum SAD-69, de onde foram coletadas as informações de latitude e longitude em UTM. As coordenadas estão registradas de acordo com a Tabela 1. A maioria das nascentes está inserida em propriedades rurais, servindo como fonte de água para a população local.

As amostras de água foram coletadas na camada superficial do corpo d’água, nos meses de outubro de 2009, fevereiro, abril e agosto de 2010. As amostras foram coletadas em frasco de polipropileno de 2 L e, em seguida, condicionadas e encaminhadas para o laboratório de Química Ambiental da Universidade Federal de Sergipe para posterior análise dos componentes de interesse. Todos os procedimentos de coleta, conservação e análise dos parâmetros - $\mathrm{pH}$, turbidez, cor, condutividade elétrica, sólidos totais solúveis, dureza, nitrato e amônia obedeceram às metodologias descritas no Standard Methods for the Examination of Water and Wastewater, American Public Health Association (APHA, 2005).

Tabela 1: Informações sobre os pontos georreferenciados no alto curso do rio Paiuitinga-SE

\begin{tabular}{cllc}
\hline Nascente & Coordenada (UTM) & \multicolumn{1}{c}{ Localizacão } & Tipo de reservatório \\
\hline $\mathbf{0 1}$ & 0656474 e 8792668 & Povoado Açú Velho & Pontual \\
$\mathbf{0 5}$ & 0658147 e 8790810 & Povoado de Açuzinho & Difusa \\
$\mathbf{0 9}$ & 0659588 e 8791072 & Povoado de Juerana & Pontual \\
$\mathbf{1 9}$ & 0657528 e 8793226 & Povoado Boa Vista do Urubu & Pontual \\
$\mathbf{2 9}$ & 0657634 e 8794284 & Povoado Brasília & Pontual \\
\hline
\end{tabular}

Fonte: Arquivo pessoal.

\section{Coleta da água e análise dos parâmetros}

Todas as análises estatísticas foram realizadas através do software SPSS 13.0 (Statistical Package for the Social Sciences). Foram selecionados apenas os fatores extraídos que apresentassem autovalores iguais ou superiores a 1 , critério também conhecido como Critério de Kaiser (MINGOTI, 2005). Desse modo, há uma redução no número de fatores mais importantes para descrição da variabilidade dos dados, pois, a partir de certo fator limite, a variância dos fatores tende a zero, sendo desnecessária a inclusão destes na nova base de dados reduzida (NONATO et al., 2007).

\section{RESULTADOS E DISCUSSÃO}

Os descritores estatísticos calculados para as variáveis da qualidade da água do rio Piauitinga estão representados na Tabela 2. 


\section{ÍNDICE DE QUALIDADE DA ÁGUA NAS NASCENTES DO RIO PIAUITINGA-SE POR ANÁLISE MULTIVARIADA E O USO NA IRRIGAÇÃO}

Os valores de $\mathrm{pH}$ estiveram entre 3,8 e 6,3, conferindo aspectos de acidez a esses corpos d’água. Magalhães (2009), em sua pesquisa, detectou que os solos da região de Lagarto-SE são ácidos, fato que justifica a ocorrência de $\mathrm{pH}$ com característica ácida principalmente no período chuvoso, uma vez que a água escoada arrasta componentes dos solos, contribuindo para o aumento da acidez dessas águas. Segundo a resolução CONAMA 357/05 as águas utilizadas na irrigação devem apresentar valores de $\mathrm{pH}$ entre 6,0 e 9,0, valores que em sua maioria não foram constatados durante a pesquisa. A acidez nas águas de irrigação é pouco debatida como fator de risco nas áreas cultivadas, porém, as salinizações das águas são pontos cruciais para perda de equipamentos e danos ao cultivo irrigado.Vasconcelos et al (2009) aponta que águas sem risco de salinidades são ideais para irrigar a maioria das culturas, na maioria dos solos. Ucker et al (2013) alertam que, a salinidade nas águas de irrigação pode diminuir a troca de água na planta e afetar o rendimento das culturas.

Tabela 2: Estatística descritiva básica das variáveis da qualidade da água do rio Piauitinga-SE.

\begin{tabular}{|c|c|c|c|c|}
\hline Parâmetros & Mínimo & Máximo & Média & Desvio Padrão \\
\hline $\mathrm{pH}$ & 3,80 & 5,80 & 5,18 & 0,55 \\
\hline Turbidez (UNT) & 2,50 & 304,00 & 44,83 & 71,66 \\
\hline Cor (mg Pt.L $\left.{ }^{-1}\right)$ & 0,20 & 96,30 & 18,27 & 27,99 \\
\hline Condutividade $\left(\mu \mathrm{S} . \mathrm{cm}^{-1}\right)$ & 81,10 & $1.375,00$ & 341,25 & 404,85 \\
\hline $\begin{array}{l}\text { Sólidos totais solúveis (STD) (mg.L- } \\
\text { 1) }\end{array}$ & 36,00 & 105,00 & 57,25 & 20,49 \\
\hline Dureza (mg. ${ }^{-1} \mathrm{CaCO}_{3}$ ) & 12,10 & 144,60 & 44,19 & 39,29 \\
\hline Nitrato (mg.L $\mathrm{L}^{-1}$ ) & 0,03 & 9,70 & 2,50 & 3,46 \\
\hline Amônia (mg. $\mathrm{L}^{-1}$ ) & 0,00 & 0,29 & 0,08 & 0,10 \\
\hline
\end{tabular}

Fonte: Acervo pessoal

Os valores de turbidez, em sua maioria, estiveram abaixo de 100 UNT, valor recomendado pela Resolução Conama $n^{\circ}$ $357 / 2005$, exceto para a nascente 5 no mês de abril, a qual é consideravelmente envolvida por vegetação de ciperáceas, o que acaba provocando a deposição de matéria orgânica e particulados nessas águas. Para Alves e Garcia (2007), o aumento significativo da turbidez no período chuvoso deve-se ao crescimento excessivo de matéria orgânica e material particulado, tais como argila, silte e areia.

Avaliando-se os valores da cor da água das nascentes, apenas as nascentes 1 e 5 , no mês de abril, apresentaram-se fora do padrão estabelecido pela Resolução Conama $n^{0}$ 357/2005, que é de $75 \mathrm{mg}$ Pt.L ${ }^{-1}$; nos demais meses todos os pontos encontram-se no limite estabelecido por esta Resolução. No que diz respeito à nascente 5, observou-se que os valores mais elevados para turbidez e cor ocorreram durante o período chuvoso, situação similar à encontrada por Alves e Garcia (2007) em estudos do Rio Poxim-SE.

Os STD apresentaram valores mais elevados durante o período chuvoso. Esta situação pode ser explicada pelo aporte de material particulado durante o período chuvoso, devido ao escoamento superficial, elevando, assim, os sólidos totais solúveis, os quais adentram nestes reservatórios com maior facilidade pela falta de vegetação ciliar às margens. Tal fato é similar ao da pesquisa de Silva (2006), que trata do perímetro irrigado Jacarecica I, diagnosticando maiores valores de STD no período chuvoso.

Os maiores registros para a condutividade elétrica ocorreram no período seco. Nesse período, a redução da vazão propicia um aumento da concentração de íons, aumentando, 
assim, a condutividade elétrica. Alves e Garcia (2007) chamam a atenção para os valores estabelecidos pela Resolução Conama $n^{0}$ $357 / 2005$, para condutividade em água doce, que varia de 10 a $1000 \mu \mathrm{S} . \mathrm{cm}^{-1}$. Já o valor de sólidos totais solúveis para as classes 2 e 3 é de 500 mg. $\mathrm{L}^{-1}$. Nesse sentido, estes parâmetros mantiveram-se dentro dos limites estabelecidos pela citada Resolução.

As concentrações de nitrato mantiveramse, respectivamente, abaixo de $10 \mathrm{mg} . \mathrm{L}^{-1}$, limite estabelecido pela Resolução Conama $n^{0}$ 357/2005 para as classes 2 e 3. Para a Embrapa (2002), teores de nitrato acima de 0,20 mg.L ${ }^{-1}$ podem favorecer o crescimento de plantas aquáticas, espécies bem visualizadas entre as águas das nascentes em estudo. Em águas naturais superficiais, normalmente, as concentrações situam-se entre 0 a $0,18 \mathrm{mg} \cdot \mathrm{L}^{-1} \mathrm{e}$ podem variar de acordo com a estação do ano (HADDAD, 2007). Esses valores também foram inferiores aos encontrados por Veline et al. (2005), onde o valor máximo foi obtido no ambiente com grande acúmulo de plantas aquáticas.

A variação da concentração de amônia distribuída nas nascentes avaliadas foi de 0,00 a 3,96 mg. $\mathrm{L}^{-1}$, o maior valor foi registrado para a nascente 9, esta constantemente visitada por bovinos, principalmente no período seco para dessedentação, o que pode justificar esse pico, indicador de excremento líquido carregado de ureia, visto não haver, nesse período, cultivo ao redor. Já a nascente 29, nesse mesmo período, é igualmente visitada, só que por banhistas. Em águas contaminadas por fertilizantes, é possível encontrar valores médios superiores a 3,0 mg. $\mathrm{L}^{-1}$ de amônia, como registrado no trabalho de Dorigon; Stolberg e Perdomo (2008), no qual os mesmos encontraram valor médio de amônia de 3,40 mg. $\mathrm{L}^{-1}$, cujo aporte do íon amônio pode ter origem nos fertilizantes nitrogenados que são demandados para culturas. Mediante os dados apresentados, não há indícios de contaminação por fertilizantes nos mananciais avaliados.

Referente à dureza, as maiores concentrações foram observadas no mês de fevereiro. Para Libânio (2005), a dureza da água pode ser classificada em mole ou branda quando apresentar concentração menor que 50 mg. $\mathrm{L}^{-1} \mathrm{CaCO}_{3}$ e dureza moderada entre 50 e $150 \mathrm{mg} . \mathrm{L}^{-1} \mathrm{CaCO}_{3}$, dessa forma as águas destas nascentes podem ser classificadas como moles. Barreto e Garcia (2010) detectaram, em trabalho no açude Buri, Frei Paulo-SE, valores de dureza na época seca de 155,6 a 165,7 mg.L${ }^{1}$ de $\mathrm{CaCO}_{3}$, coincidindo com a faixa de valor encontrado em fevereiro neste trabalho. Os resultados de Alves et al. (2006) variaram de 20,46 a 147,3, com um valor médio de 71,0 $\mathrm{mg} . \mathrm{L}^{-1} \mathrm{em}$ águas do rio Poxim-SE, pouco acima do encontrado neste trabalho. Para esses autores, a dureza é causada, principalmente, pela presença de sais de cálcio e magnésio, juntamente com íons polivalentes como ferro, alumínio, manganês e zinco.

A análise multivariada partiu de uma matriz de 08 x 20 (linhas x colunas), sendo as linhas representando os parâmetros, e as colunas, observações. As variáveis consideradas foram $\mathrm{pH}$, turbidez, cor, condutividade elétrica (CE), sólidos totais solúveis (STD) dureza, nitrato $\left(\mathrm{NO}_{3}{ }^{-}\right)$e amônia $\left(\mathrm{NH}_{4}{ }^{+}\right)$, enquanto as observações foram as coletas realizadas.

Inicialmente, a matriz de dados foi transformada na matriz de correlação de Pearson (Tabela 3), que permite identificar as variáveis mais significativas, ou seja, aquelas que apresentarem coeficientes de correlação maiores que $|0,5|$ (WANG et al., 2010).

Assim, há correlação significativa entre $\mathrm{pH}$ e dureza, ou seja, o aumento do pH está associado a um aumento da dureza. O mesmo pode ser verificado com a turbidez e cor, além da cor e a concentração de amônia e da condutividade elétrica e dureza. A amônia apresentou correlação negativa com os sólidos totais solúveis e dureza, indicando que o aumento de uma variável provoca redução na outra. Pode-se verificar, de acordo com a Tabela 3, que a variável nitrato não apresentou correlação superior a $|0,5|$, por este motivo esta variável foi excluída da análise fatorial. 

MULTIVARIADA E O USO NA IRRIGAÇÃO

Tabela 3: Matriz de correlação das variáveis originais de qualidade da água no rio Piauitinga-SE.

\begin{tabular}{|c|c|c|c|c|c|c|c|c|}
\hline $\mathrm{pH}$ & $\begin{array}{l}\mathrm{pH} \\
1,00\end{array}$ & Turbidez & Cor & CE & STD & Dureza & $\mathrm{NO}_{3}{ }^{-}$ & $\mathrm{NH}_{4}$ \\
\hline Turbidez & $-0,11$ & 1,00 & & & & & & \\
\hline Cor & 0,21 & 0,61 & 1,00 & & & & & \\
\hline CE & 0,48 & $-0,25$ & $-0,20$ & 1,00 & & & & \\
\hline STD & $-0,40$ & 0,06 & $-0,17$ & $-0,07$ & 1,00 & & & \\
\hline Dureza & 0,53 & $-0,31$ & $-0,25$ & 0,96 & $-0,07$ & 1,00 & & \\
\hline $\mathrm{NO}_{3}^{-}$ & $-0,10$ & $-0,29$ & $-0,07$ & 0,06 & $-0,26$ & $-0,03$ & 1,00 & \\
\hline $\mathrm{NH}_{4}$ & $-0,03$ & 0,46 & 0,67 & $-0,49$ & $-0,51$ & $-0,53$ & 0,01 & 1,00 \\
\hline
\end{tabular}

Fonte: Acervo pessoal

Para verificar se a análise fatorial é adequada aos dados, foi aplicado o teste Kaiser-Meyer-Olkin (KMO), através da medida de adequação da amostra, com o objetivo de comparar os coeficientes de correlação observados com os parciais. O intervalo de validade do teste KMO, para aplicação do modelo de análise de fator, de acordo com Hair et al. (2009), é apresentado na
Tabela

Tabela 4: Orientação para aplicação da análise fatorial de acordo com a medida do KMO

\begin{tabular}{cc}
\hline Medida KMO & Orientação \\
\hline$\geq 0,8$ & Admirável \\
$\geq 0,7$ & Mediano \\
$\geq 0,6$ & Medíocre \\
$0,6-0,5$ & Ruim \\
$\leq 0,5$ & Inaceitável \\
\hline
\end{tabular}

Fonte: Hair et al. (2009).

Em geral, um valor acima de 0,5 é o recomendável antes de se proceder à análise fatorial. Um valor abaixo de 0,5 indica que os valores específicos da adequação da amostra podem identificar variáveis para eliminação para atingir um valor acima de 0,5 (HAIR et al., 2009). O valor encontrado para a medida de adequação da amostra foi de 0,563 , adequado, portanto, para seguir com a análise.

Com a aplicação do teste de esfericidade de Bartlett, verificou-se que a matriz de correlação gerada é próxima ou não da matriz identidade (MINGOTI, 2005). O teste de esfericidade de Bartlett foi estatisticamente significante (sign. < 0,05), indicando que existem correlações suficientes entre as variáveis para se continuar a análise.

Para determinar os fatores que representam a variabilidade da qualidade da água, sem haver muita perda de informações, foi realizada a análise fatorial. A técnica de componente principal foi utilizada para a extração dos fatores. Considerando ainda o critério de Kaiser, no qual os autovalores dos fatores devem ser maiores que 1 , foram obtidos três fatores, que explicam $75,1 \%$ da variância das variáveis originais (Tabela 5).

Tabela 5: Matriz dos autovalores da matriz de correlação das variáveis da qualidade da água do rio Piauitinga-SE

\begin{tabular}{cccc}
\hline \multirow{3}{*}{ Componente } & \multicolumn{3}{c}{ Autovalores } \\
& Total & Variância & \% Variância Acumulada \\
\hline 1 & 3,10 & 38,77 & 38,77
\end{tabular}




\begin{tabular}{lccc}
$\mathbf{2}$ & $\mathbf{1 , 8 1}$ & $\mathbf{2 2 , 6 6}$ & $\mathbf{6 1 , 4 2}$ \\
$\mathbf{3}$ & $\mathbf{1 , 3 9}$ & $\mathbf{1 7 , 3 7}$ & $\mathbf{7 8 , 7 9}$ \\
4 & 0,86 & 10,81 & 89,60 \\
5 & 0,42 & 5,30 & 94,90 \\
6 & 0,26 & 3,22 & 98,12 \\
7 & 0,12 & 1,48 & 99,60 \\
8 & 0,03 & 0,40 & 100,00 \\
\hline
\end{tabular}

Fonte: Acervo pessoal

Com base nos resultados apresentados, foram estimadas as cargas fatoriais não rotacionadas; estas indicam o grau de correspondência entre a variável e o fator, cargas maiores tornam a variável representativa do fator (Tabela 6). Foram consideradas cargas fatoriais maiores que $|0,7|$ como indicativas de estruturas bem definidas e significativas (HAIR et al., 2009).

Também foram determinadas as comunalidades que representam um índice útil, pois permitem avaliar quanto de variância em uma variável particular é explicada pela solução fatorial. Valores altos indicam que uma grande quantia da variância em uma variável foi extraída pela solução fatorial, ao contrário das comunalidades com valores pequenos. Um mínimo de 0,50 para comunalidades e cargas fatoriais excedendo $|0,7|$ são consideradas indicativas de estruturas bem definidas (HAIR et al., 2009).

Tabela 6: Matriz de análise fatorial de componentes não rotacionados e comunalidades

\begin{tabular}{|c|c|c|c|c|}
\hline \multirow{2}{*}{ Variáveis } & \multicolumn{3}{|c|}{ Componentes } & \multirow{2}{*}{ Comunalidades } \\
\hline & 1 & 2 & 3 & \\
\hline $\mathrm{pH}$ & 0,50 & 0,65 & $-0,14$ & 0,70 \\
\hline Turbidez & $-0,61$ & 0,24 & 0,60 & 0,79 \\
\hline Cor & $-0,66$ & 0,43 & 0,46 & 0,84 \\
\hline Condutividade elétrica & 0,82 & 0,34 & 0,37 & 0,94 \\
\hline Sólidos totais solúveis & 0,07 & $-0,79$ & 0,50 & 0,88 \\
\hline Dureza & 0,86 & 0,33 & 0,32 & 0,96 \\
\hline $\mathrm{NH}_{4}$ & $-0,78$ & 0,54 & $-0,17$ & 0,92 \\
\hline
\end{tabular}

Observando a Tabela 4, nota-se que a componente 3 não apresentou nenhuma variável com carga fatorial superior a 0,7 . Nesse sentido, para maximizar a relação entre as variáveis e os componentes, foi aplicada a rotação dos fatores pelo método Varimax (Tabela 7). Este processo maximiza a variância entre os componentes, alterando a raiz característica sem afetar a proporção da variância total explicada pelo conjunto, além de minimizar a ocorrência de uma variável e possuir altas cargas fatoriais para diferentes fatores, permitindo que uma variável seja facilmente identificada com um único fator (ANDRADE et al., 2007; CORRAR et al., 2007).

Tabela 7: Matriz das cargas de fatores comuns rotacionada pelo método Varimax

\begin{tabular}{lccc}
\hline \multirow{2}{*}{ Variáveis } & \multicolumn{3}{c}{ Componentes } \\
\cline { 2 - 4 } & $\mathbf{1}$ & $\mathbf{2}$ & $\mathbf{3}$ \\
\hline $\mathrm{pH}$ & 0,60 & $-0,13$ & 0,56 \\
Turbidez & $-0,11$ & $\mathbf{0 , 8 8}$ & $-0,10$ \\
Cor & $-0,13$ & $\mathbf{0 , 9 0}$ & 0,13 \\
Condutividade elétrica & $\mathbf{0 , 9 6}$ & $-0,11$ & $-0,01$
\end{tabular}


Sólidos totais solúveis

Dureza

$\mathrm{NH}_{4}$
$-0,05$

0,96

$-0,46$
$-0,04$

$-0,18$

0,59
$-0,94$

0,01

0,60
Dessa forma, no primeiro fator as variáveis mais importantes foram condutividade elétrica e dureza, representando o conteúdo mineral, uma vez que essas variáveis estão relacionadas com os cátions e ânions existentes na água. Resultados semelhantes foram encontrados por Aguiar et al. (2013). Portanto, essas são as variáveis mais importantes na determinação da qualidade da água para essas nascentes. A condutividade elétrica relaciona-se com sais não naturais dissolvidos na água, que podem ter sua origem nas atividades desenvolvidas nessas nascentes, como as de lazer, através de banhos, lavagem de roupas, dentre outras.

O segundo fator apresenta como variáveis significativas a cor e a turbidez. Essas variáveis estão relacionadas com o escoamento superficial, principalmente devido às práticas agrícolas, como também ao aporte de efluentes e resíduos sólidos dispostos inadequadamente às margens dos cursos d'água (ANDRADE et al., 2007).

O terceiro fator apresenta apenas uma variável com carga fatorial superior a $|0,7|$, que são os sólidos totais solúveis.

As águas das nascentes apresentaram a inter-relação dos compostos naturais tal como uso e ocupação do solo nesta bacia, onde entre os fatores contribuintes para anormalidade de alguns parâmetros estão a degradação da mata ciliar, pastagem e utilização das nascentes para lavagem de roupas. Entretanto, os valores finais apresentados enquadram essas águas na classe 2. Essa classificação permite diversos usos, dentre estes o abastecimento humano e irrigação, sem grandes investimentos para a purificação da mesma para tais demandas.

\section{CONCLUSÃO}

A análise fatorial através das técnicas Análise de Componente Principal/Análise de
Fatores Comuns resultou na redução de nove parâmetros para três componentes indicadores da qualidade da água do rio Piauitinga, explicando 78,79\% da variância total. Dessa forma, as melhores condições para descrever o índice de qualidade de água foram determinadas. A rotação ortogonal pelo método Varimax dos fatores mostrou que as variáveis da qualidade da água estão relacionadas principalmente com o conteúdo mineral, escoamento superficial e com os sólidos totais solúveis. No entanto, as condições climáticas, a degradação da mata e o ambiente externo podem afetar a qualidade de água para irrigação.

\section{REFERENCIAS BIBLIOGRÁFICA}

AGUIAR NETTO, A. O. MENDONÇA FILHO, C. J. M. ROCHA, J. C. Águas de Sergipe: Reflexões sobre o cenário e limitações. In: Meio Ambiente: Distintos olhares. 1 ed. São Cristóvão/SE. Ed. UFS, 2007. 178 p.

ALVES, J. P. H, GRACIA, C. A. B. Qualidade da água. In: AGUIAR NETTO, A. O et al. Diagnóstico e avaliação ambiental da sub-bacia hidrográfica do rio Poxim. Relatório final. UFS. FAPESE, Aracaju-SE. 2007.

ALVES, J. P.H; GARCIA, C. A. B; AGUIAR NETTO, A. O; FERREIRA, R. A; SANTOS, D. S. B; BARBOSA, C. D. E. S; COSTA, A. S. Rio Poxim: Qualidade da água e suas variações sazonais. In: XVII Simpósio Brasileiro de Recursos Hídricos, 2006. Anais. São Paulo: ABRH.

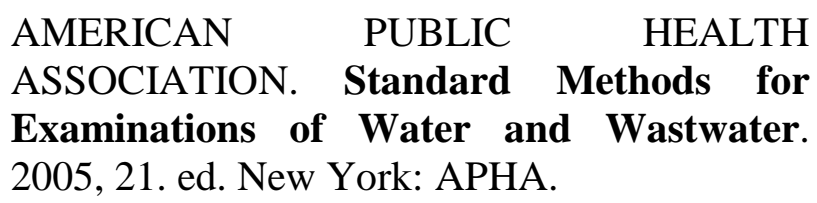


ANDRADE, E. M.; ARAÚJO, L. F. P.; ROSA, M. F.; GOMES, R. B.; LOBATO, F. A. O. Fatores determinantes da qualidade das águas superficiais na bacia do Alto Acaraú, Ceará, Brasil. Revista Ciência Rural, Santa Maria, v. 37, n.6, 2007, p. 1791-1797.

BARRETO, P. R; GARCIA, C. A. B. Caracterização da qualidade da água do açude Buri-Frei Paulo-SE. Revista.Scientia Plena. Sergipe, v.6, n.9, 2010, p.1-21.

BOMFIM, L. F. C; COSTA, I. V. G.; BENVENUTI, S. M. P. Projeto Cadastro da Infra-Estrutura Hídrica do Nordeste: Estado de Sergipe. Diagnóstico do Município de Pirambu. Aracaju: CPRM, 2002.

BOMFIM, J. W; ALMEIDA, U. S; SANTANA, M. P. N. A. Preservação no entorno das nascentes na sub-bacia do rio Piauitinga no município de Lagarto - SE. Brasil: Uma proposta para educação ambiental. 2009. Disponível em: $<$ http://egal2009.easyplanners.info/area07/7008 _ALMEIDA_UENDEL_SOUZA.pdf $>$. Acesso em 20.06.2010.

BRASIL, Resolução CONAMA 357/2005. Classificação dos corpos d'água e diretrizes para o seu enquadramento e condições e padrões de lançamento de efluentes. Disponível em: <http://www.mma.gov.br/port/CONAMA/ >. Acesso em 03 de março de 2009.

BUSS, D. F. Desenvolvimento de um índice biológico para um índice biológico para uso de voluntários na avaliação da qualidade dos rios. Revista Oecol, Brasil, v.212, n.3, 2008, p.520530.

CARVALHO, A. C. de L; SANTANA, J. L. Direito ambiental brasileiro em perspectiva: Aspectos legais, críticas e atuação prática. 1 ed. Curitiba. Ed. Juruá, 2009, 528 p.

CASTRO, P. S. Recuperação e conservação de nascentes. Viçosa. Ed. CPT, 2007, 272p.
COHIDRO. Companhia de desenvolvimento e de recursos hídricos e irrigação de Sergipe. Dados meteorológicos do perímetro irrigado no município de Lagarto-SE. 2010.

CORRAR, L. J.; PAULO, E.; DIAS FILHO, J. M. Análise Multivariada: para os cursos de administração, ciências contábeis e economia. São Paulo: Atlas, 2007, 541 p.

DORIGON, E. B; STOLBERG, J; PERDOMO, C. C. Qualidade da água em uma microbacia de uso agrícola e urbano em Xanxerê - SC. Revista Ciências Ambientais, Canoas, v.2, n.2, 2008, p. 105-120.

EMBRAPA. Empresa Brasileira de Pesquisa Agropecuária. Indicadores da qualidade da água. 2002. Disponivel em:<http://www.embrapa.com.br.> acesso em: 14 de agosto 2010.

FONTES, A. L; SANTOS, A. F. Diagnóstico ambiental preliminar na sub-bacia do rio Piauitinga-SE. Dissertação (Mestrado em Geografia)-Universidade Federal de Sergipe, São Cristóvão, 1999.

HADDAD, E. A. Influência antrópica na qualidade da água da bacia hidrográfica do rio São Miguel, carste do alto São Francisco, Minas Gerais. Dissertação (Mestrado em geografia)-Universidade Federal de Minas Gerais, Belo Horizonte. 2007.

HAIR, J. J. F.; ANDERSON, R.E.; TATHAM, R.L.; BLACK, W.C. Análise multivariada de dados. 6. ed. Porto Alegre: Bookman, 2007, $688 \mathrm{p}$.

IBGE. Instituto Brasileiro de Geografia e Estatística. Cidades@. 2010. Disponível em:<http://www.ibge.gov.br/estadosat/perfil.ph p?sigla=se\# $>$.Acesso em: 30 jun. 2010

IBGE. Instituto Brasileiro de Geografia e Estatística IBGE: Produção Agrícola Municipal 2008.

Disponível 
em:<www.ibge.gov.br/cidadesat/topwindow.ht m?1 acesso em 03 de julho de 2010.

KUMARESAN, M; RIYAZUDDIN, P. Factor analysis and linear regression model (LRM) of metal speciation and physico-chemical characters of groundwater samples. Environmental Monitoring and Assessment, v. 138, n. 1-3, 2008, p. 65-79.

LIBANIO, M. Fundamentos da qualidade da água. ed. Campinas/SP. Ed. Átomo, 2005, $444 p$.

MAGALHÃES, L. T. S. Qualidade dos solos nas áreas de nascentes do alto curso do rio Piauitinga, Lagarto-SE 2009. Dissertação (Mestrado em Agroecossistemas)-Universidade Federal de Sergipe, São Cristóvão.

MINGOTI, S.A. Análise de dados através de métodos de estatística multivariada: uma abordagem aplicada. Editora UFMG: Belo Horizonte. 2005.

NONATO, E. A.; VIOLA, G. G.; ALMEIDA, K. C. B.; SCHOR, H. H. R. Tratamento estatístico dos parâmetros da qualidade das águas da bacia do Alto Curso do Rio das Velhas. Revista Química Nova, Brasil, v. 30, n.4, 2007, p. 797-804.

OLIVEIRA, N. L. Agricultura e meio ambiente: Sistemas agrícolas e sustentabilidade ambiental na sub bacia do rio Piauitinga (SE). In. Relatório de Iniciação Científica PIBIC/CNPq-2001/2002. 2002.

PINTO, L. V. A; BOTELHO, S. A; DAVIDE, A. C; FERREIRA, E.. Estudo das nascentes da bacia hidrográfica do Ribeirão Santa Cruz, Lavras, MG. Revista Scientia Forestalis, Brasil, n.65, 2004, p.197-206.

SANTOS, C. M. Ruralidades agrícolas e não agrícolas em Lagarto-SE. 2009, Tese (Doutorado em geografia)- Universidade Federal de Sergipe.
SCHAGERL, M.; BLOCH, I.; ANGELER, D. G.; FELS, C. The use of urban clay-pit ponds for human recreation: assessment of impacts on water quality and phytoplankton assemblages. Environmental Monitoring and Assessment, v. 165, 2010, p. 283-293.

SEMARH. Secretaria do estado de meio ambiente e recursos hídricos. Elaboração dos planos das bacias hidrográficas dos rios Japaratuba, Piauí e Sergipe, 2010, 471p.

SILVA, M. G. Caracterização da qualidade da água na barragem do perímetro irrigado Jacarecica I, Itabaina-SE. 2006. Dissertação (mestrado em Agroecossistema)-Universidade Federal de Sergipe.

SOJKA, M.; SIEPAK, M.; ZIOLA, A.; FRANKOWSKI, M.; MURATBLAZEJEWSKA, S.; SIEPAK, J. Application of multivariate statistical techniques to evaluation of water quality in the Mała Wełna River (Western Poland). Environmental Monitoring and Assessment, v. 147, n. 1-3, 2008, p. 159-170.

SOH MD, S. C.; ABDULLAH, P. Determination of volatile organic compounds pollution sources in malaysian drinking water using multivariate analysis. Environmental Monitoring and Assessment, v. 124, 2007, p. 39-50.

SONG, M. W.; HUANG, P.; LI, F.; ZHANG, H.; XIE, K. Z.; WANG, X. H.; HE, G. X. Water quality of a tributary of the Pearl River, the Beijiang, Southern China: implications from multivariate statistical analyses. Environmental Monitoring and Assessment, v. 172, 2010, p. 589-603.

SRH. Secretaria de recursos hídricos. BOMFIM, L. F.C; COSTA, I. V. G; BENVENUTI, S. M. P. Diagnóstico do município de Lagarto: Projeto cadastro da infra-estrutura hídrica do nordeste. Sergipe. 2002, 35p 
TUCCI, C. E. M. Gestão da água no Brasil. ed. Brasília. Ed. UNESCO, 2001, 156 p.

UCKER, F. E; LIMA, P. B. S. O; CAMARGO, M. F; PENA, D. S; CARDOSO, F. C; PÊGO, A. W. E. Elementos interferentes na qualidade da água para irrigação. Rev. Elet. em Gestão, Educação e Tecnologia Ambiental. v(10), $\mathrm{n}^{0}$ 10, p. 2102-2111, JAN-ABR, 2013.

VASCONCELOS, R. S; LEITE, K. N; CARVALHO, C. M; ELOI, W. M; DA SILVA, L. M; FEITOSA, O. F. Qualidade da água utilizada para irrigação na extensão da microbacia do baixo Acaraú. Rv. Bras. Agric. Irrigada v.3, n.1, p.30-38 2009.
VELINI, E. D; NEGRISOLI, E; CAVENAGHI, A.L; CORRÊA, M.R; BRAVIN, L. F.N; DE MARCHI, S.R; TRINDADE, M. L. B; ARRUDA, D.P; PADILHA, F. S. Caracterização da qualidade de água e sedimento na UHE Americana relacionados à ocorrência de plantas aquáticas. Revista Scielo, Brasil, v.23, n.2. 2010, p.215-223.

WANG, L.; WANG, Y.; XU, C.; AN, Z.; WANG, S. Analysis and evaluation of the source of heavy metals in water of the River Changjiang. Environmental Monitoring and Assessment, v. 173, n. 1-4, 2010, p. 301-313. 